\title{
M2M Architecture for Enhancing the Public Transportation Management Services Using ARM7
}

\author{
Ashwini V. Borse', M. D. Jakhete ${ }^{2}$ \\ ${ }^{1}$ ME Digital Electronics, GHRIEM, Jalgaon, India \\ ${ }^{2}$ Assistant Professor, GHRIEM, Jalgaon, India
}

\begin{abstract}
The project aims in designing a system which is capable of predicting the bus travel time and sending the travel time to the user on his request. The system makes use of GSM modem and GPS receiver along with Microcontrollers to achieve the task. Travel time information is a vital component of many intelligent transportation systems (ITS) applications. In this proposed system we introduced advanced public transportation systems (APTS) for public service. Advanced public transportation systems (APTS) are one of the most important applications, which can significantly improve the traffic situation in India. One such application will be to provide accurate information about bus arrivals to passengers, leading to reduced waiting times at bus stops. This needs a real-time data collection technique, a quick and reliable prediction technique to calculate the expected travel time based on real-time data and informing the passengers regarding the same. The scope of this proposed system is to use global positioning system data collected from public transportation buses plying on urban roadways, India, to predict travel times. The performance of the proposed system is found to be promising and expected to be valuable in the development of advanced public transportation systems (APTS) in India. The work presented here is one of the first attempts at real-time short-term prediction of travel time in Indian traffic conditions. The controlling devices of the whole system are Microcontrollers. The project makes use of two Microcontroller based systems; one in the bus and other at bus depot. The user needs to send his source and destination in the predefined SMS format to the bus depot number. The SMS will be received by GSM modem in bus depot and fed to Microcontroller. The Microcontroller sends an SMS through GSM modem to the system in bus with that source and destination. The system in the bus calculates the time required to reach the user location basing on the GPS data of current location and predefined user location data and sends this time information to the user mobile. This helps the people in saving the valuable time from waiting at bus stops. The Microcontrollers used in the project are programmed using Embedded C language.
\end{abstract}

Keywords: ARM7 (LPC2148), GSM, GPS

\section{Introduction}

Current bus services are congested, unreliable, untimely and uncoordinated in India. The ownership and operation of most public transport services have significantly reduced its productivity. India's cities desperately necessitate improved and trustworthy public transport service. The public transport needs to scale the productivity with increasing population and its needs, the improvement in infrastructure must be assisted with the smart approaches of Machine-toMachine (M2M) communication. This social issue has encouraged us to come up with an idea for the betterment.

This proposal best describes a low cost and frugal, yet practical solution for the concerned problem using GSM/GPRS as a communication medium. The usability of public transport can be enhanced by informing the real waiting time and occupancy/vacancy to the passengers. So the main objective of this paper is to give a possible solution to implement the proposed changes in existing public transport system to enhance its usability and profitability.

\section{System Design}

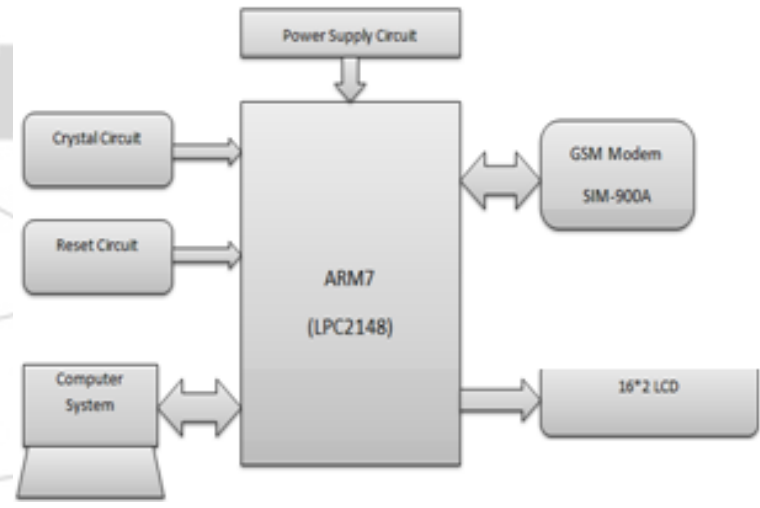

Figure 1: Block Diagram of System on the Bus stop

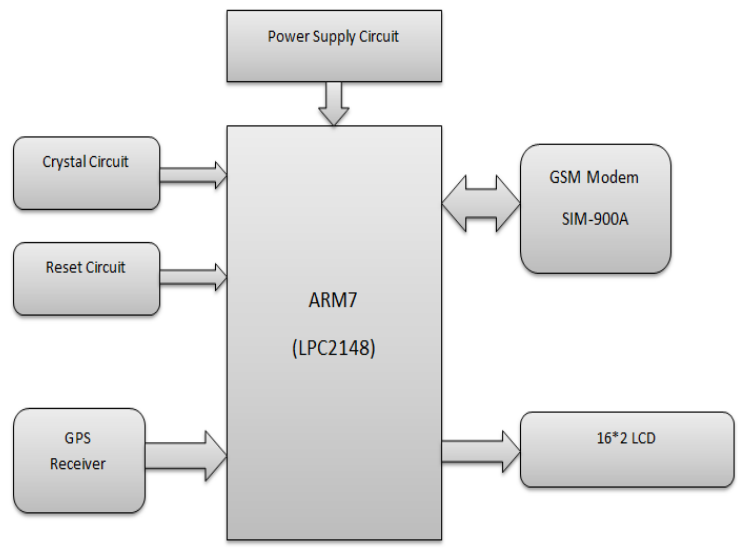

Figure 2: Block Diagram of System in the Bus 


\section{International Journal of Science and Research (IJSR) \\ ISSN (Online): 2319-7064}

Index Copernicus Value (2013): 6.14 | Impact Factor (2015): 6.391

\section{A. ARM7 (LPC2148)}

The LPC2141/42/44/46/48 microcontrollers are based on a 16-bit/32-bit ARM7TDMI-S CPU with real-time emulation and embedded trace support, that combine the microcontroller with embedded high-speed flash memory ranging from $32 \mathrm{kB}$ to $512 \mathrm{kB}$. The LPC2141/42/44/46/48 microcontrollers are based on a 16-bit/32-bit ARM7TDMI-S CPU with real-time emulation and embedded trace support, that combine the microcontroller with embedded high-speed flash memory ranging from $32 \mathrm{kB}$ to $512 \mathrm{kB}$. A 128-bit wide memory interface and a unique accelerator architecture enable 32 bit code execution at maximum clock rate. For critical

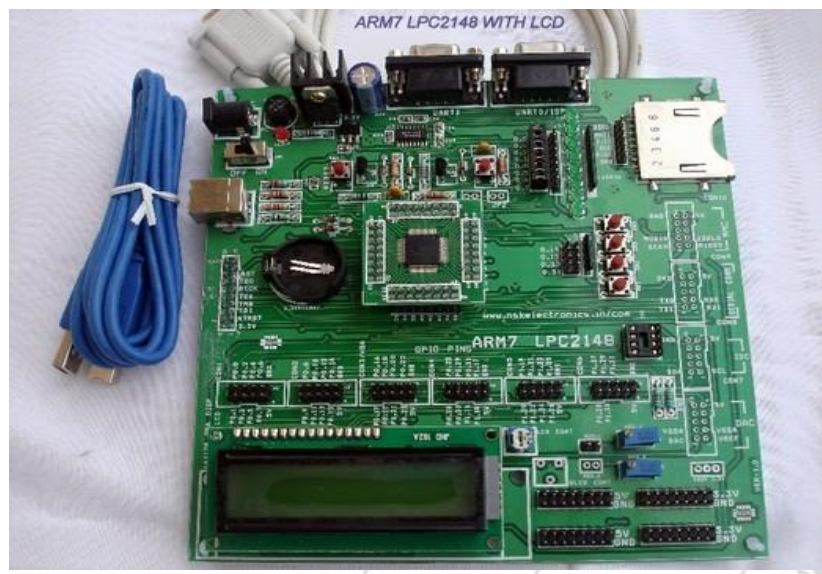

Figure 3: ARM7 (LPC2148)
System/European Geostationary Navigation Overlay Service) functionality for more accurate positioning results.

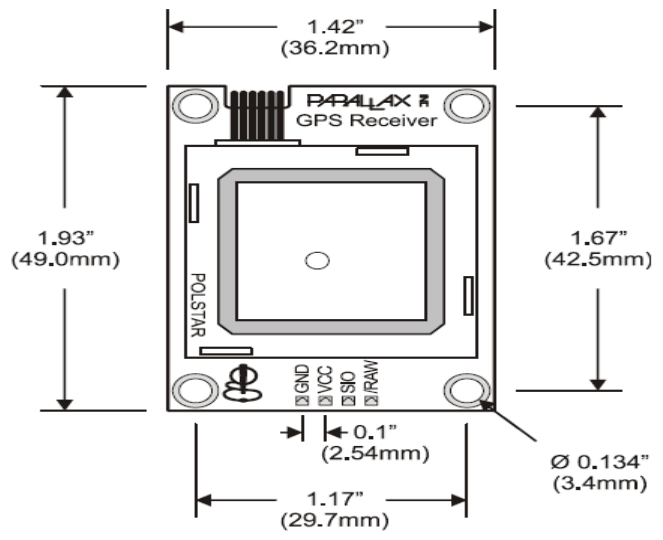

Figure 4: GPS Receiver

The Module provides current time, date, latitude, longitude, altitude, speed, and travel direction/heading, among other data, and can be used in a wide variety of hobbyist and commercial applications, including navigation, tracking systems, mapping, fleet management, auto-pilot, and robotics.

\section{SIM900 Module}

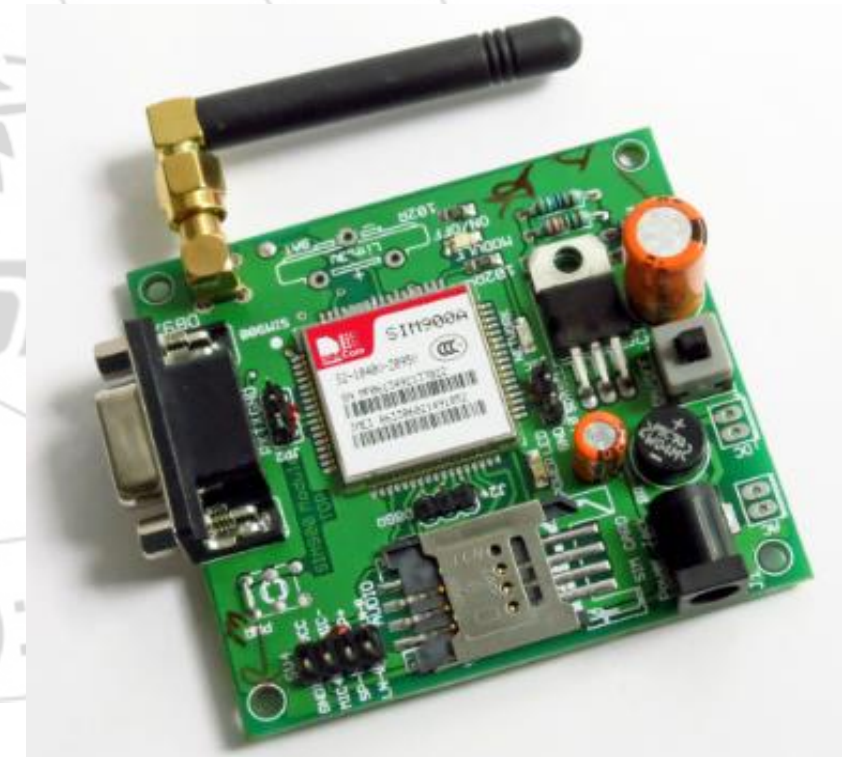

Figure 5: SIM900 module

The SIM900 is a complete Quad-band GSM/GPRS solution in a SMT module which can be embedded in the customer applications. Featuring an industry-standard interface, the SIM900 delivers GSM/GPRS 850/900/1800/1900MHz performance for voice, SMS, Data, and Fax in a small form configuration of $24 \mathrm{~mm} \times 24 \mathrm{~mm} \times 3 \mathrm{~mm}$, SIM900 can fit almost all the space requirements in your M2M application, especially for slim and compact demand of design.

\section{Experimental Set Up}

The following figure shows some part of hardware of project.
The GPS Receiver Module provides standard, raw
NMEA0183 (National Marine Electronics Association) strings or specific user-requested data via the serial command interface, tracking of up to 12 satellites, and WAAS/EGNOS (Wide Area Augmentation 


\section{International Journal of Science and Research (IJSR) \\ ISSN (Online): 2319-7064}

Index Copernicus Value (2013): 6.14 | Impact Factor (2015): 6.391

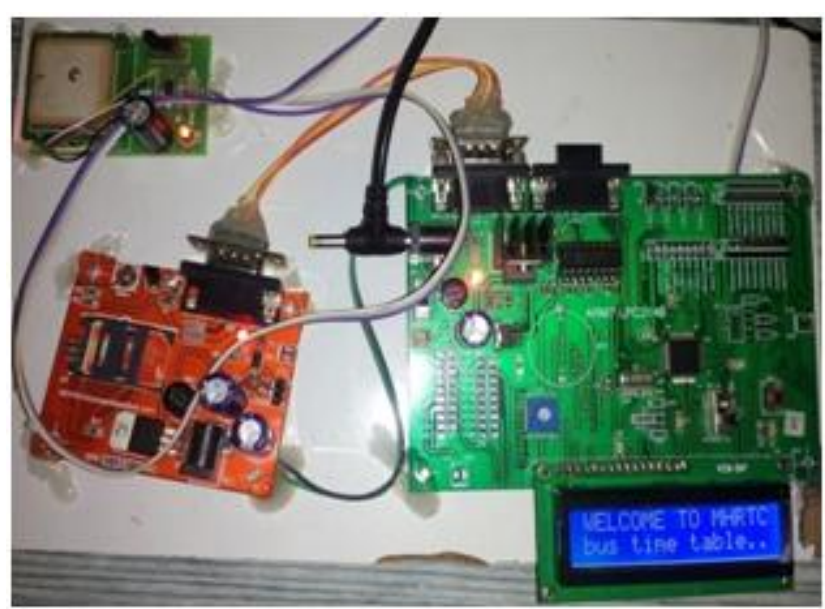

Figure 6 : Reading on LCD screen on setup in the bus

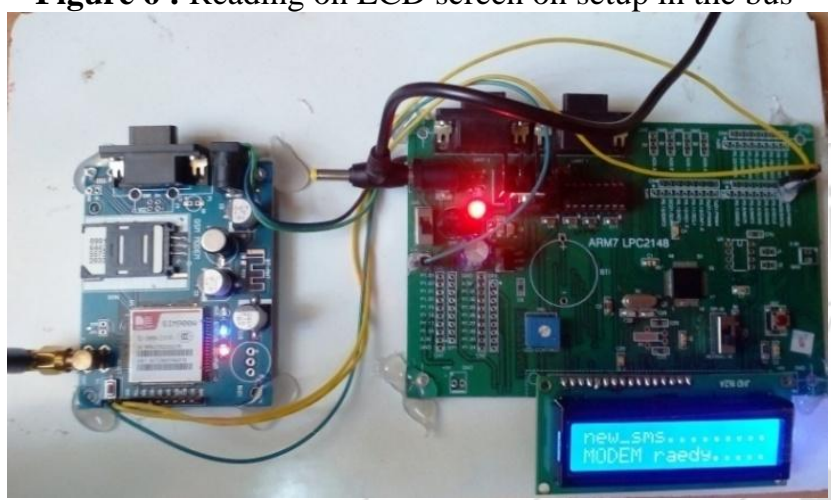

Figure 7: Reading on LCD screen on setup on bus stop

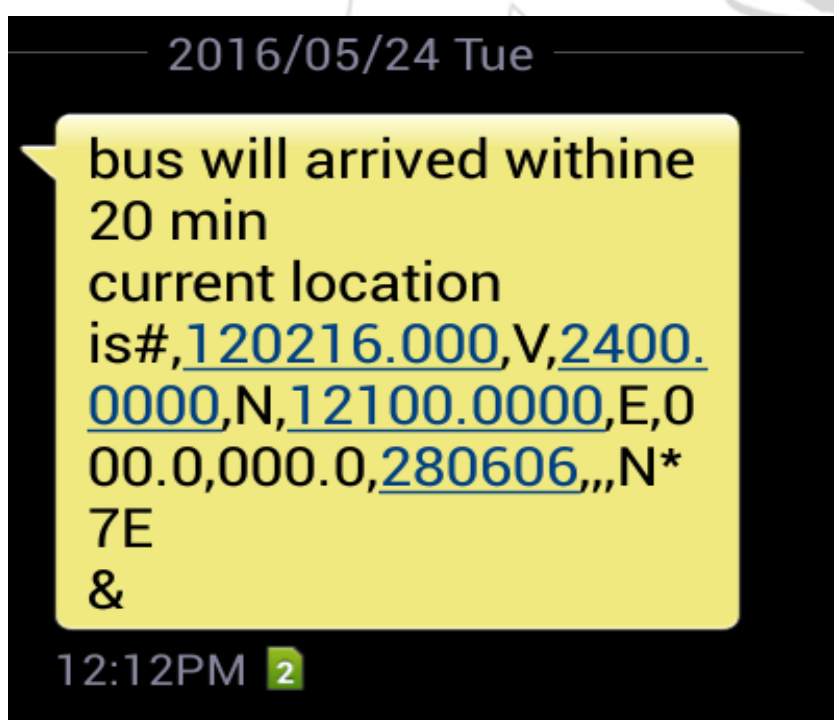

Figure 8: Reading from mobile

Values of longitude and latitude will be received on mobile in the form of SMS.

\section{Conclusion}

This paper designs the system which gives location and arrival time of city bus. Using of private vehicles is increasing in a rapid growth, which results in a constant traffic jam in a day to day life. This proposed system allows to Improved and trustworthy public transport services may lead to the solution of the mentioned problem. Setting up a coordinated small distance and long distance wireless communication network for public transportation, providing accurate information about the arrival time. The general result is that the system proved to be reliable as to view the positioning of the devices.

\section{References}

[1] G. Bhavya, Dr. K. Raghava Rao, "Intelligent Public Transport Management System Using Embedded Technology" National Conference on Advancements in Embedded Systems and Sensor Networks (AESSN 2015).

[2] Nikhil Magdum, Aman Maldar, Sushant Patil, Sunil Tamhankar, "A Low Cost M2M Architecture for Intelligent Public Transit - An approach to Modernise City Public Transport for Developing Countries." International Conference on Pervasive Computing (ICPC) -1-4799-6272-3/15/2015 IEEE.

[3] Se Gi Hong, SungHoonSeo, Henning Schulzrinne and Prabhakar Chitrapu. "ICOW: Internet Access in Public Transit System", IEEE Communication Magazine, June 2015.

[4] Ganguri Rakesh, "Prototypic Gps-Gsm Integration for Enhancing Public Transportation and Management Services." International Journal of Engineering Research and Applications www.ijera.com ISSN : 2248-9622, Vol. 4, Issue 7( Version 5), July 2014, pp.28-33

[5] Saed Tarapiah, Shadi Atalla, Rajaa AbuHania, " Smart On-Board Transportation Management System Using GPS/GSM/GPRS Technologies to Reduce Traffic Violation in Developing Countries" International Journal of Digital Information and Wireless Communications (IJDIWC) 3(4): 430-439 The Society of Digital Information and Wireless Communications, 2013 (ISSN: 2225-658X)

[6] "Intelligent Transport Systems In India" by European Business and Technology Centre (EBTC), A Report 2012

[7] Se Gi Hong, SungHoonSeo, Henning Schulzrinne and Prabhakar Chitrapu. "ICOW: Internet Access in Public Transit System", IEEE Communication Magazine, June 2015. 